\title{
Photocatalytic Degradation of Municipal Wastewater and Brilliant Blue Dye Using Hydrothermally Synthesized Surface-Modified Silver-Doped ZnO Designer Particles
}

\author{
Tabasom Parvin, ${ }^{1,2}$ Namratha Keerthiraj, ${ }^{1}$ Ibrahim Ahmed Ibrahim, ${ }^{3}$ \\ Sukhon Phanichphant, ${ }^{4}$ and Kullaiah Byrappa ${ }^{1}$ \\ ${ }^{1}$ Crystal Growth and Materials Science Laboratory, Department of Earth Science, University of Mysore, P.B. No. 21, \\ Manasagangothri P.O., Mysore 570006, India \\ ${ }^{2}$ DOS in Environmental Science, University of Mysore, P.B. No. 21, Manasagangothri P.O., Mysore 570006, India \\ ${ }^{3}$ Central Metallurgical Research and Development Institute CMRDI, Hellwan 11471, Egypt \\ ${ }^{4}$ Materials Science Research Center, Faculty of Science, Chiang Mai University, Chiang Mai 50200, Thailand \\ Correspondence should be addressed to Kullaiah Byrappa, kbyrappa@gmail.com
}

Received 4 September 2011; Accepted 16 October 2011

Academic Editor: David Lee Phillips

Copyright ( $\odot 2012$ Tabasom Parvin et al. This is an open access article distributed under the Creative Commons Attribution License, which permits unrestricted use, distribution, and reproduction in any medium, provided the original work is properly cited.

Photocatalytic degradation of local municipal wastewater and brilliant blue FCF dye were investigated using silver-doped ZnO designer particles. The silver-doped $\mathrm{ZnO}$ designer particles were synthesized under mild hydrothermal conditions $(T=150$ $250^{\circ} \mathrm{C}, P=$ autogeneous, experimental duration $=16-24 \mathrm{~h}$ ) in the presence of surface modifiers. The resultant products were characterized using powder XRD, FTIR, Zeta potential, and SEM. Various parameters including catalyst amount, light source, $\mathrm{pH}$, and photocatalytic time duration were studied to find out their effects on photodegradation efficiency with respect to municipal wastewater and brilliant blue dye. The effect of these parameters was evaluated using chemical oxygen demand (COD) and \% transmittance analyses. The photodegradation results showed that the surface-modified silver-doped ZnO designer particles had higher efficiency compared to the reagent-grade $\mathrm{ZnO}$ in photodegradation of municipal wastewater and brilliant blue dye.

\section{Introduction}

Water is a basic requirement in all industrial, domestic, and commercial activities; the wastewater generated from these various processes contains a wide range of contaminants depending upon the process. These effluents are intensely colored and are contaminated with a high concentration of organic compounds such as suspended and dissolved salts and many other recalcitrant compounds. Heterogeneous photocatalysis is a promising method among advanced oxidation processes (AOPs), which can be used for degradation of various organic pollutants in water and wastewater [1]. Until now, many kinds of semiconductor metal oxide nanoparticles have been studied as photocatalyst including $\mathrm{TiO}_{2}$, $\mathrm{ZnO}$, and $\mathrm{WO}_{3}$ [2]. $\mathrm{ZnO}$ is known as an important semiconductor, which has been studied extensively in the past few years due to its fundamental and technological characteristics. Its various attractive properties, such as wide-band gap $(3.37 \mathrm{eV})$, large excitation-binding energy $(60 \mathrm{meV})$, and excellent chemical stability suggest a host of possible practical applications as gas sensors [3], ceramics [4], field emission devices [5], luminescent materials [6], biomedical [7], and photocatalysis [8]. Therefore, $\mathrm{ZnO}$ has been considered as one of the important materials, and its applications are expanding continuously [9]. However, $\mathrm{ZnO}$ nanoparticles are prone to aggregate due to the large surface area and high surface energy. In order to improve the dispersion, it is necessary to modify the surface of $\mathrm{ZnO}$ nanoparticles [10, 11]. Hence, an appropriate capping agent or organic ligand or surfactant or chelating agent is added to achieve a control over the size and morphology for these $\mathrm{ZnO}$ particles, and thereby the properties could be effectively tailored 
[12]. $\mathrm{ZnO}$ nanoparticles can be synthesized by various methods including sol-gel processing [13], homogeneous precipitation [14], mechanical milling [15], organometallic synthesis [16], microwave method [17], spray pyrolysis [18], thermal evaporation [19], mechanochemical synthesis [20], and solvothermal and hydrothermal techniques [21, 22]. The hydrothermal technique provides an excellent possibility for processing the advanced materials whether as bulk single crystals, or fine particles, or nanoparticles owing to a highly controlled diffusion in a closed system under mild temperature pressure conditions [23]. The designer particles mean particles with desired or tailor-made physicochemical characteristics [24]. In the present study, authors report the synthesis and characterization of in situ surface-modified silver-doped $\mathrm{ZnO}$ polyscale crystals and their application in the photodegradation of municipal wastewater and brilliant blue dye. $n$-hexanol is known as a tertiary alcohol which has a strong affinity to silver dopant, and it is expected to bring enhanced catalytic activity for the $\mathrm{ZnO}$ nanoparticles.

\section{Experimental}

2.1. Preparation of Modified Silver-Doped ZnO Designer Particles. Silver-doped $\mathrm{ZnO}$ polyscale crystals were fabricated under hydrothermal conditions $\left(\mathrm{T}=150-250^{\circ} \mathrm{C}, P=\right.$ autogeneous, experimental duration $=16-24 \mathrm{~h}) .1 \mathrm{M}$ of reagentgrade $\mathrm{ZnO}$ (Loba Chemie, India) was taken as starting material, and the silver metal (Loba Chemie, India) dopant taken in $1 \mathrm{M} \%, 3 \mathrm{M} \%$, and $5 \mathrm{M} \%$ concentration was added into it. A required amount of $1 \mathrm{~N} \mathrm{NaOH}$ (Loba Chemie, India) mineralizer was added into the precursor. $n$-hexanol (Sisco Research Laboratories Pvt. Ltd. Mumbai, India) with different concentrations $(0.1,0.3$, and $0.5 \mathrm{M})$ was added into the above-mentioned mixture, and it was stirred vigorously for a few minutes. The final compound was then transferred into the Teflon liner $\left(V_{\text {fill }}=10 \mathrm{~mL}\right)$, which was later placed inside a General-Purpose autoclave. Then the autoclave assembly was kept in an oven with a temperature programmer-controller for 16-24h. The temperature was maintained at a desired temperature in the region $150-250^{\circ} \mathrm{C}$ depending upon the surface modifier. After the experimental run, the autoclave was cooled to the room temperature. The $\mathrm{pH}$ was measured before and after the experimental run, and the initial and final $\mathrm{pH}$ values were maintained at 10 . The product in the Teflon liner was then centrifuged at $25,000 \mathrm{rpm}$ at $4^{\circ} \mathrm{C}$ for $15 \mathrm{~min}$ and then freeze-dried. The freeze-dried particles were subjected to a systematic characterization and photocatalytic studies.

2.2. Characterization of the Modified Silver-Doped $\mathrm{ZnO}$ Designer Particles. The designer particles fabricated were characterized using different analytical techniques. The powder X-ray diffraction patterns were recorded using Rigaku Miniflex II, with $\mathrm{CuK} \alpha, \lambda: 1.542 \AA$ radiation, voltage $: 30 \mathrm{kV}$, current : $15 \mathrm{~mA}$, scan speed $\sim 5^{\circ} \mathrm{min}^{-1}$, and the $2 \theta$ range was kept between 10 and $80^{\circ}$. The Fourier transform infrared spectra were recorded using FTIR, JASCO-460 PLUS, Japan at resolution of $4 \mathrm{~cm}^{-1}$. SEM study was carried out to know the size and morphology of the crystals obtained using JEOL JSM 5410LV (Japan). Zeta potential was measured using Zeta Sizer 2000 (Malvern instruments, UK).

\subsection{Photocatalytic Degradation of Municipal Wastewater and} Brilliant Blue Dye. In photocatalytic system, a combination of semiconductors (such as $\mathrm{TiO}_{2}, \mathrm{ZnO}, \mathrm{F}_{2} \mathrm{O}_{3}$, and $\mathrm{ZnS}$ ) and UV or visible lights can be used. Wastewater sample was collected from the influent of Mysore City Municipal wastewater treatment plant, Mysore, India. For photodegradation studies, a known volume of the wastewater sample and dye solution of normality $1 \times 10^{-5} \mathrm{M}(50 \mathrm{~mL})$ were taken in separate beakers. A known amount of the catalyst was added to this. The photodegradation experiment was carried out under both UV and visible-light irradiation. In order to know the effect and efficiency of the compound synthesized, the blank sample was used and the comparison was made with the results obtained. The intensity of sunlight and UV light was estimated by photolysis of uranyl oxalate [25]. It was estimated that the intensity of sunlight was $6.522 \times$ $10^{16}$ quanta/s, and the intensity of UV was $2.375 \times 10^{15}$ quanta/s. The chemical oxygen demand (COD) was estimated before and after the treatment (using Open Reflux method). The photodegradation efficiency of the synthesized compound was calculated using the equation

$$
\text { Photodegradation efficiency }=\frac{\text { Initial }_{\mathrm{COD}}-\text { Final }_{\mathrm{COD}}}{\text { Initial }_{\mathrm{COD}}} \text {. }
$$

\section{Result and Discussion}

3.1. XRD Patterns of Modified Silver-Doped ZnO Designer Particles. The XRD patterns of pure $\mathrm{ZnO}$, surface-modified $\mathrm{ZnO}, 1 \mathrm{M} \%$ Ag-doped $\mathrm{ZnO}, 3 \mathrm{M} \% \mathrm{Ag}$, and $5 \mathrm{M} \% \mathrm{Ag}$-doped $\mathrm{ZnO}$ match well with the JCPDS file number 800075 . The cell parameters and cell volumes of the compounds were calculated using checkcell. Figure 1, clearly, shows that there is no major shift in the peaks positions. As evident from the cell parameters given in Table 1, we can conclude that silver does not enter into the structure replacing $\mathrm{Zn}^{2+}$, but it might be entering interstitially. However, it is well-known that silver as a strong catalyst has a close affinity to the alkoxide like $n$-hexanol, and it adsorbs the organics and forms a capping $[26,27]$. With a rise in the concentration of silver-like $5 \mathrm{M} \%$, there are several smaller intensity peaks in the powder XRD pattern in addition to the main $\mathrm{ZnO}$ peaks. The powder XRD data reveals a highly crystallized wurtzite structure and homogeneous phase formation in case of lower concentration of silver doping.

\subsection{FTIR Spectroscopic Studies of Modified Silver-Doped $\mathrm{ZnO}$} Designer Particles. The presence of dopants, metal oxide, and other functional groups of the compound was identified by FTIR studies. It is well-known that FTIR gives minute internal structural details of the materials, and such details cannot be observed through the routine X-ray diffraction studies, which give an ideal overall picture of the structure. On contrary, the FTIR spectra give information on the 


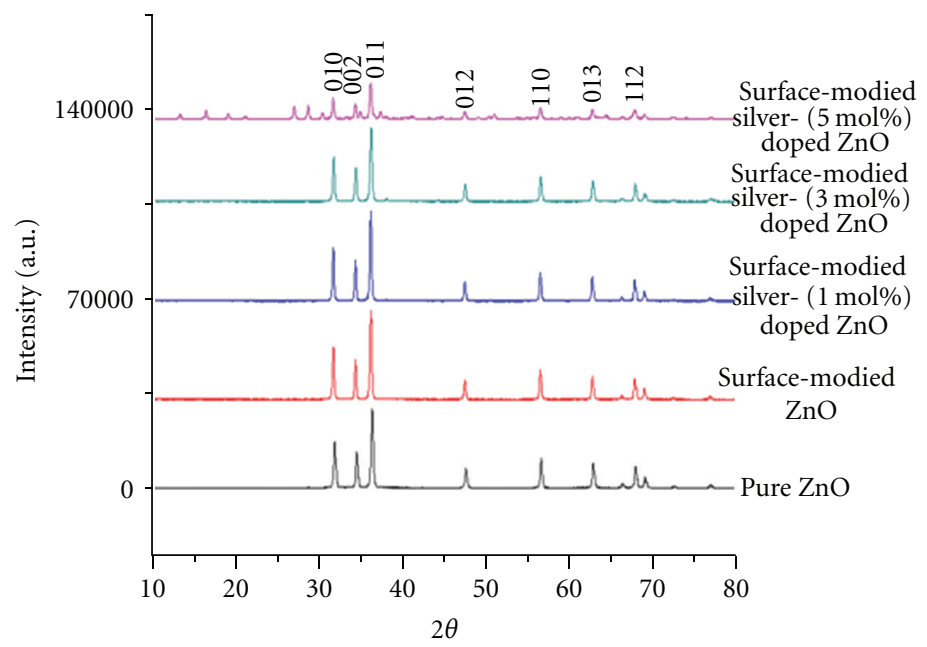

FIGURE 1: Powder XRD patterns of modified silver-doped ZnO designer particles.

TABLe 1: Cell parameters of $\mathrm{ZnO}$ synthesized.

\begin{tabular}{lccc}
\hline Catalyst & $\mathrm{a}(\AA)$ & $\mathrm{c}(\AA)$ & $\mathrm{V}\left(\AA^{3}\right)$ \\
\hline Reagent grade ZnO & 3.2530 & 5.2059 & 47.71 \\
Surface modified ZnO & 3.2477 & 5.2011 & 47.51 \\
$1 \mathrm{M} \%$ Silver-doped ZnO & 3.2491 & 5.2011 & 47.55 \\
3 M\% Silver-doped ZnO & 3.242 & 5.194 & 47.45 \\
$5 \mathrm{M} \%$ Silver-doped ZnO & 3.2484 & 5.1993 & 47.51 \\
\hline
\end{tabular}

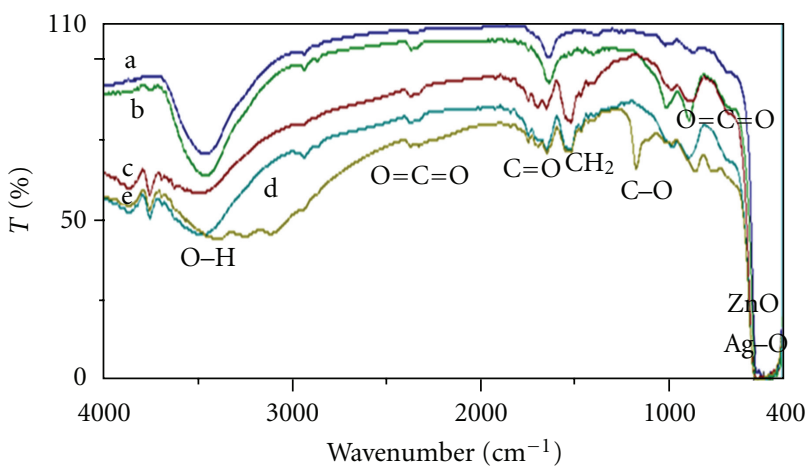

Figure 2: FTIR spectra of: (a) reagent grade $\mathrm{ZnO}$; (b) undoped ZnO-modified with $0.5 \mathrm{M} n$-hexanol; (c) $1 \mathrm{M} \% \mathrm{Ag}$ doped $\mathrm{ZnO}$ modified with $0.3 \mathrm{M} n$-hexanol; (d) $3 \mathrm{M} \%$ Ag-doped $\mathrm{ZnO}$ modified with $0.3 \mathrm{M} n$-hexanol; (e) $5 \mathrm{M} \%$ Ag-doped $\mathrm{ZnO}$ modified with $0.3 \mathrm{M} n$-hexanol.

presence or absence of other components like carbonates, hydroxyls, several organic molecules, and so forth. Figure 2 shows the FTIR spectra of the reagent-grade $\mathrm{ZnO}$, undoped surface-modified $\mathrm{ZnO}$, silver- (1, 3, and $5 \mathrm{M} \%$ ) doped $\mathrm{ZnO}$ with $n$-hexanol as surface modifier. Based on the FTIR study, we can conclude that the surface modifier used in the

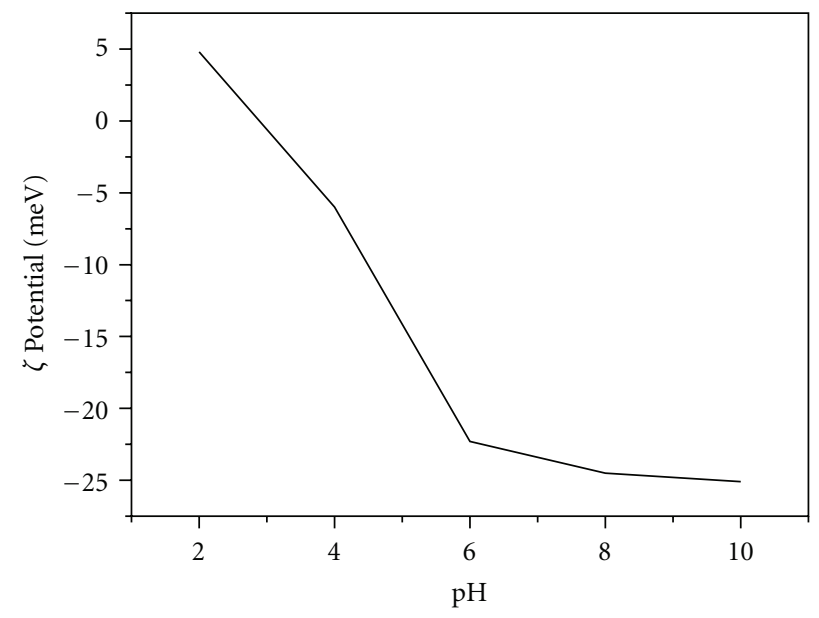

FIGURE 3: Zeta potential of silver-doped $\mathrm{ZnO}$ designer particles modified with $n$-hexanol as surfactant.

fabrication of the compounds has played a significant role in the formation of these designer nanoparticulates and has formed strong organic cappings on the silver dopant than zinc oxide, because of the strong affinity of $n$-hexanol to the silver. Although the experimental products were thoroughly washed thrice and freeze-dried, the organics were not removed from the products. This is evident from the FTIR spectra of the resultant products. As observed from Figure 2, with an increase in the concentration of silver, the absorption bands due to the presence of several organics groups are seen in the region $875-1450 \mathrm{~cm}^{-1}$. $n$-hexanol boils at about $151.3^{\circ} \mathrm{C}$, and experimental temperature is $180^{\circ} \mathrm{C}$, and it even breaks down into several other organic groups in the presence of $\mathrm{NaOH}$ as a solvent under hydrothermal conditions. The literature survey shows the presence of such absorption bands of organics due to the splitting of $n$ hexanol, particularly in the region $875-990 \mathrm{~cm}^{-1}[28,29]$. 


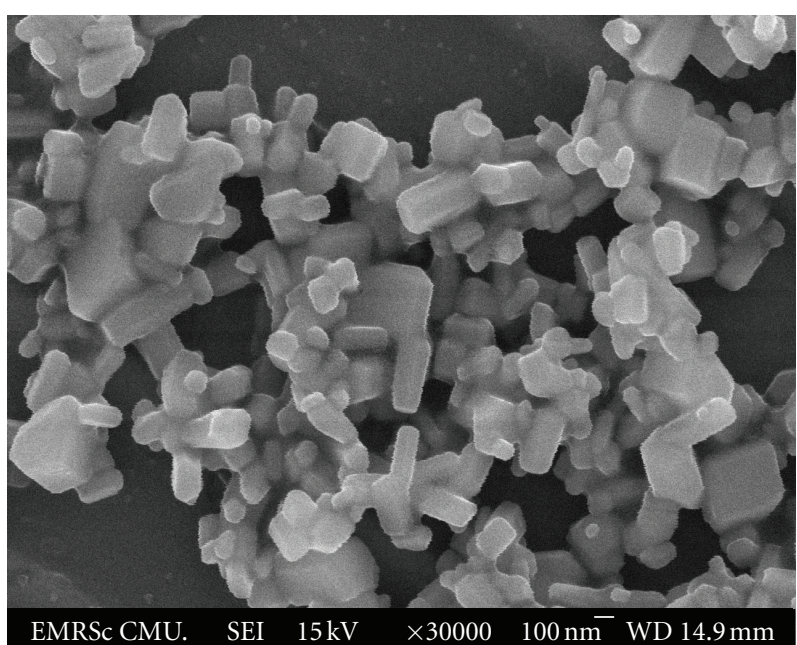

(a)

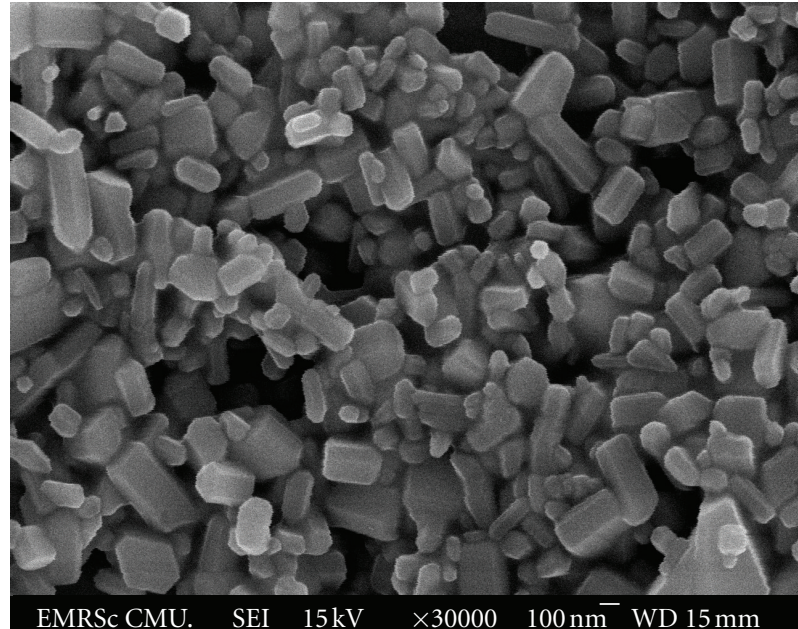

(b)

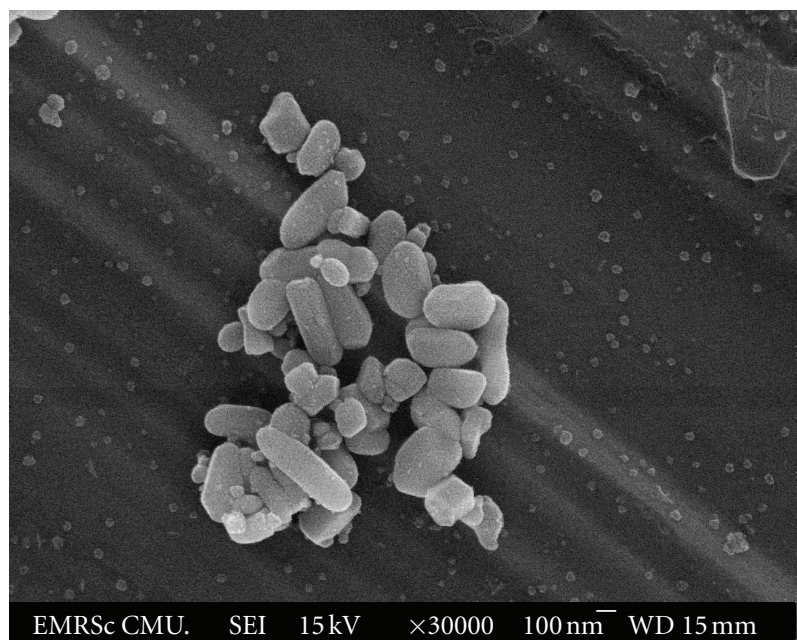

(c)

Figure 4: SEM images of (a) $1 \mathrm{M} \%$ silver-doped $\mathrm{ZnO}$ modified with $0.3 \mathrm{M} n$-hexanol, (b) $3 \mathrm{M} \%$ silver-doped ZnO modified with $0.3 \mathrm{M}$ $n$-hexanol, and (c) $5 \mathrm{M} \%$ silver-doped $\mathrm{ZnO}$ modified with $0.3 \mathrm{M} n$-hexanol.

The band in the region $438 \mathrm{~cm}^{-1}$ to $453 \mathrm{~cm}^{-1}$ represents the stretching mode of $\mathrm{Zn}-\mathrm{O}$. The peaks in the region $419 \mathrm{~cm}^{-1}$, $443 \mathrm{~cm}^{-1}$, and $497 \mathrm{~cm}^{-1}$ represent the absorption peaks of $\mathrm{Ag}$. The band in the region within $3000 \mathrm{~cm}^{-1}$ to $3800 \mathrm{~cm}^{-1}$ corresponds to the $\mathrm{OH}^{-}$band, which is due to the absorption of water molecules during the process of recording FTIR spectra and near $1600 \mathrm{~cm}^{-1}$ is the $\mathrm{C}=\mathrm{O}$ stretching mode. The band near $2360 \mathrm{~cm}^{-1}$ is because of the absorption of atmospheric $\mathrm{CO}_{2}$ on the metallic cations. The band at $1450 \mathrm{~cm}^{-1}$ corresponds to $\mathrm{CH}_{2}$ and the band at $1170 \mathrm{~cm}^{-1}$ belongs to the $\mathrm{C}-\mathrm{O}$ bond. When the concentration of silver is $1 \mathrm{M} \%$, the FTIR spectrum looks less split and smooth, where as an increase in the concentration of silver introduces more stronger absorption bands due to organics capping of silver in the region $1170-878 \mathrm{~cm}^{-1}$.

\subsection{Zeta Potential of Surface-Modified Silver-Doped $\mathrm{ZnO}$} Designer Particles. Zeta potential $(\zeta)$ measurement was performed to study the stability of polyscale crystals. Figure 3 shows the $\zeta$ measurement results as a function of $\mathrm{pH}$. The obtained $\zeta$ potential of modified silver-doped $\mathrm{ZnO}$ polyscale crystals was found to decrease with increase of $\mathrm{pH}$ as is expected for a surface with acid-base group. The iso-electric point of zero charge (PZC) for $\mathrm{ZnO}$ polyscale crystals was found to be 3.1 for modification by $n$-hexanol. For smaller nanoparticles, a high $\zeta$ potential will confer stability, that is, the solution or dispersion will resist aggregation. When the $\zeta$ is low, attraction exceeds repulsion, and the dispersion will break and flocculate [30].

3.4. SEM Images of $Z n O$ Designer Particles. Figure 4 shows the characteristic SEM images of 1,3, and $5 \mathrm{M} \%$ of modified silver-doped $\mathrm{ZnO}$ designer particles with $0.3 \mathrm{M} n$-hexanol modifier. The surface modification has led to the controlling of growth direction, and also particle size and preventing agglomeration. It was found that the surface modifier could not only affect the disper-sibility of the synthesized $\mathrm{ZnO}$ designer particles, but it did also change particles 


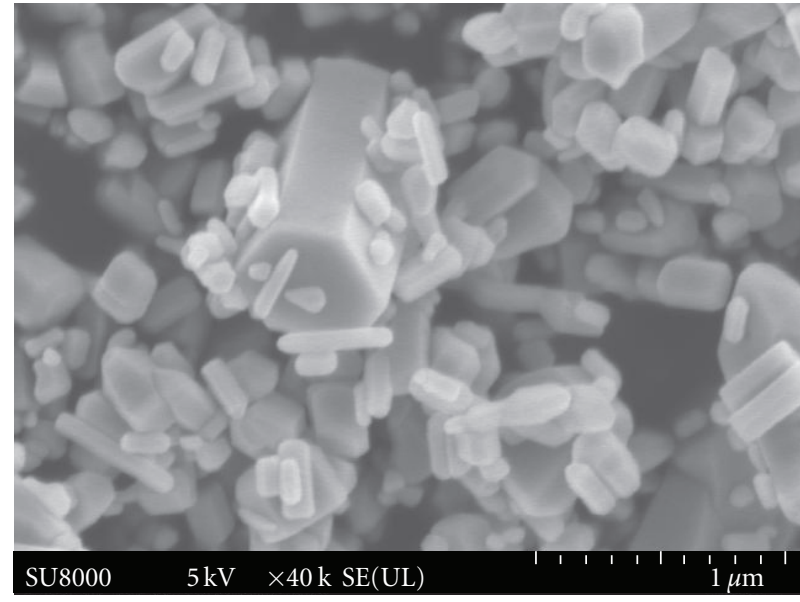

(a)

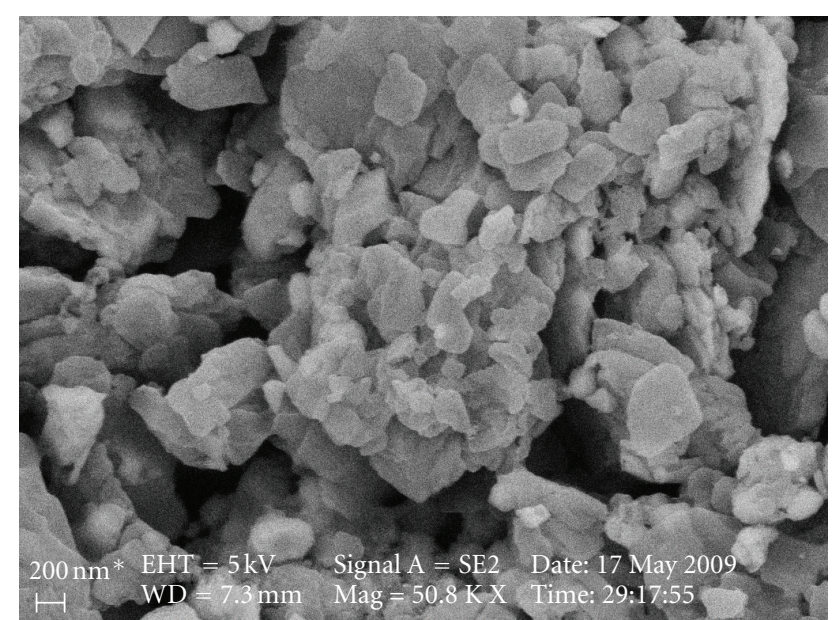

(b)

FIGURE 5: SEM images of (a) $5 \mathrm{M} \%$ silver-doped $\mathrm{ZnO}$ modified with $0.5 \mathrm{M}$ gluconic acid and (b) $5 \mathrm{M} \%$ silver-doped ZnO modified with $2 \mathrm{M}$ caprylic acid.

morphology and size. In order to know the effect of surface modifier on the synthesis of $\mathrm{ZnO}$ designer particles, the results obtained were compared with $\mathrm{ZnO}$ synthesized with other surface modifiers like caprylic acid and gluconic acid. These experiments were carried out at $250^{\circ} \mathrm{C}$ over $24 \mathrm{~h}$ duration for caprylic acid and at $150^{\circ} \mathrm{C}$ for $16 \mathrm{~h}$ for gluconic acid. Figure 5 shows SEM images of caprylic acid and gluconic acid modified silver-doped $\mathrm{ZnO}$. The presence of surplus $\mathrm{ZnO}(4 \mathrm{M})$ has introduced large agglomeration. Similarly surplus surfactant has simply led to the formation of bulk aggregates without any specific morphology. Instead the particles have irregular shape and also vary in size when the concentration of silver was increased to 4 and $5 \mathrm{M} \%$, the formation of larger and elongated particles of $\mathrm{ZnO}$ along with small particles of silver chloride attached over the surface of $\mathrm{ZnO}$ was observed. The agglomeration of particles continues in spite of the presence of surface modifier in the system. In fact, surplus amount of surface modifier reduces the quality of the particles and introduces more agglomeration. In contrary, SEM images do not show larger particle size, and agglomeration in the presence of $n$ hexanol surface modifier. Interestingly, SEM images of the experimental products obtained with $n$-hexanol modifier do not show the silver metal particles attached to the larger size $\mathrm{ZnO}$ particles. Here the particles are more dispersed compared to the silver-doped $\mathrm{ZnO}$ nanoparticles obtained with caprylic acid, or gluconic acid modifiers. SEM images depict that the crystals exhibit different morphologies with different size and shapes. Most of the crystals are tabular, elongated structure, and hexagonal in shape. The morphology achieved is quite suitable for the photodegradation purposes. The average aspect ratios of the synthesized designer particles given in Figures 4(a), 4(b), and 4(c) are $1: 1.8,1: 2.5$, and $1: 1.9$, respectively. Therefore, $\mathrm{ZnO}$ designer particles are attractive catalysts, in part, simply because of their high surface area while the increased surface area of $\mathrm{ZnO}$ designer particles is a relatively simple consequence of reducing their size and aspect ratio.
3.5. Effect of Amount of Silver-Doped ZnO Designer Particles on Photodegradation Efficiency. Photodegradation efficiency of pure $\mathrm{ZnO}$ and silver-doped $\mathrm{ZnO}$ designer particles was studied using municipal wastewater sample and Brilliant Blue dye. The experiment was carried out over a duration of $3 \mathrm{~h}$ under both sunlight and UV light. The photodegradation experiment was carried out using different weights of modified silver-doped $\mathrm{ZnO}$ photocatalyst. The effect of different weights of catalyst $(30-70 \mathrm{mg})$ on the degradation of the municipal wastewater is given in Figure 6. The photodegradation efficiency was increased up to $69 \%$ under sunlight and $49 \%$ under UV light. Figure 6 clearly shows that the effect of degradation increases with respect to weight of catalyst and increases in detention time. Similarly for the degradation of Brilliant Blue dye $20-80 \mathrm{mg}$ of the catalyst was used. The photodegradation efficiency of the catalyst on brilliant blue is given in Figure 7. The photodegradation efficiency was increased up to $94.4 \%$ under sunlight and $77.7 \%$ under UV light. The values obtained in terms of increase in photodegradation efficiency with respect to the weight of catalyst used and detention time for the degradation of municipal wastewater sample when exposed under sunlight and UV light are given in Table 2. It is well known that as the organics present in dye solution decreases, percentage transmission increases. In case of municipal wastewater, the sample collected was colorless and percentage transmission was not measured. However, when the photodegradation experiment was carried using brilliant blue dye, the $\% T$ was recorded before and after the experiment. The graphical representation in the increase in $\% T$ of the dye solution is given in Figure 8. The maximum percentage transmission of 97.14\% was obtained using silver-doped $\mathrm{ZnO}$ for a duration of $3 \mathrm{~h}$ under sunlight and maximum $\% \mathrm{~T}$ of $72.52 \%$ as obtained under UV light. The result shows that silverdoped polyscale crystal is more effective than undoped $\mathrm{ZnO}$ crystals. The best degradation results were achieved using $1 \mathrm{M} \%$ silver-doped $\mathrm{ZnO}$ designer particles, and the maximum degradation was achieved under sunlight when 


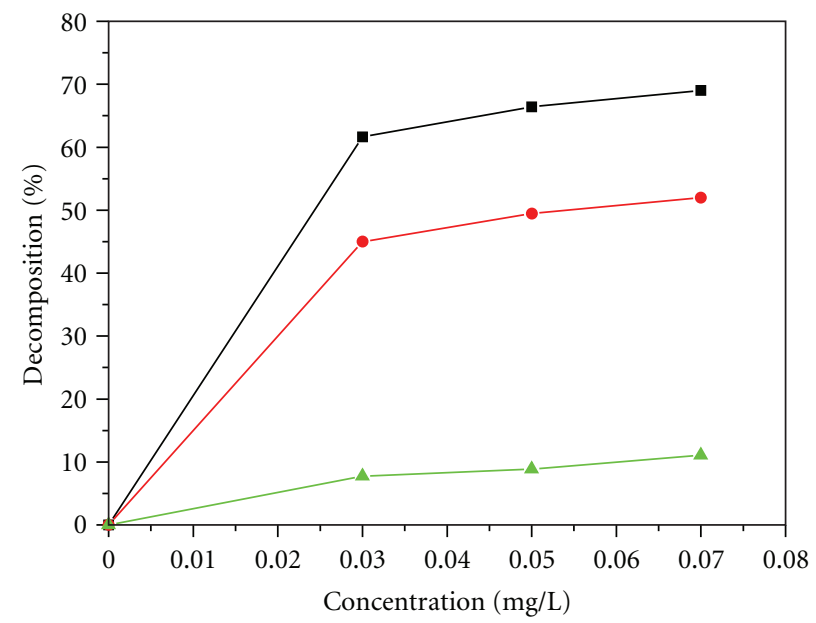

(a)

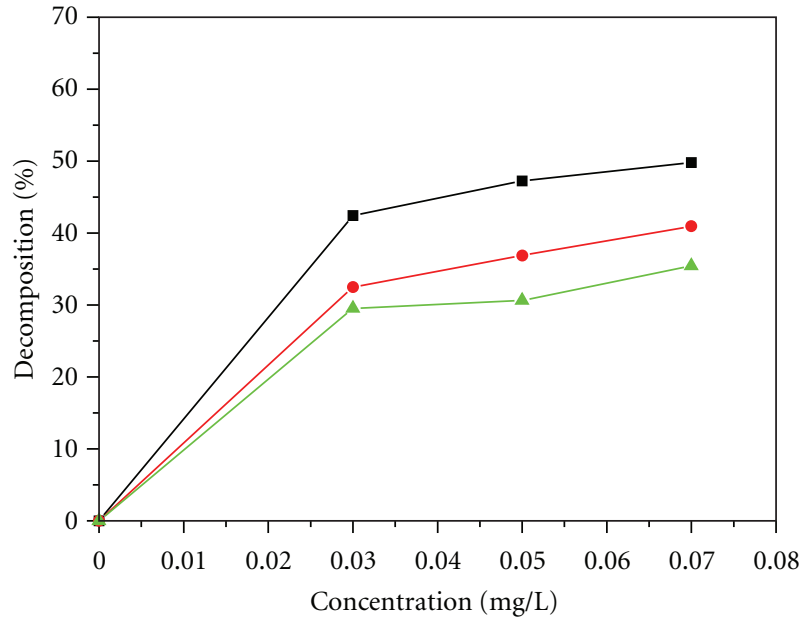

(b)

FIGURE 6: Effect of catalyst dosage on the photodegradation efficiency: (a) under sunlight, (b) under UV light irradiation: ( $\mathbf{\Delta}$ ) reagent grade $\mathrm{ZnO}$ and (ם) $1 \%$ Ag-doped $\mathrm{ZnO}$ modified with $0.3 \mathrm{M} n$-hexanol; (•) 3\% Ag-doped ZnO modified with $0.3 \mathrm{M} n$-hexanol.

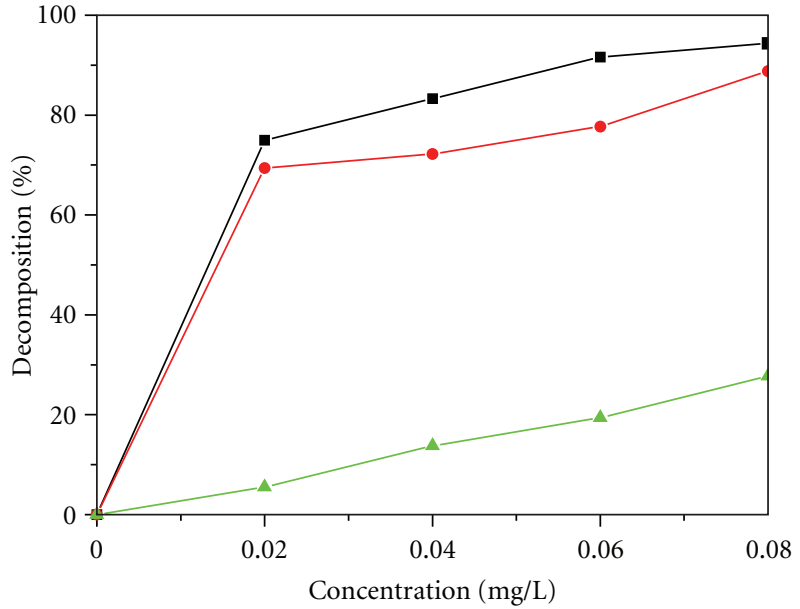

(a)

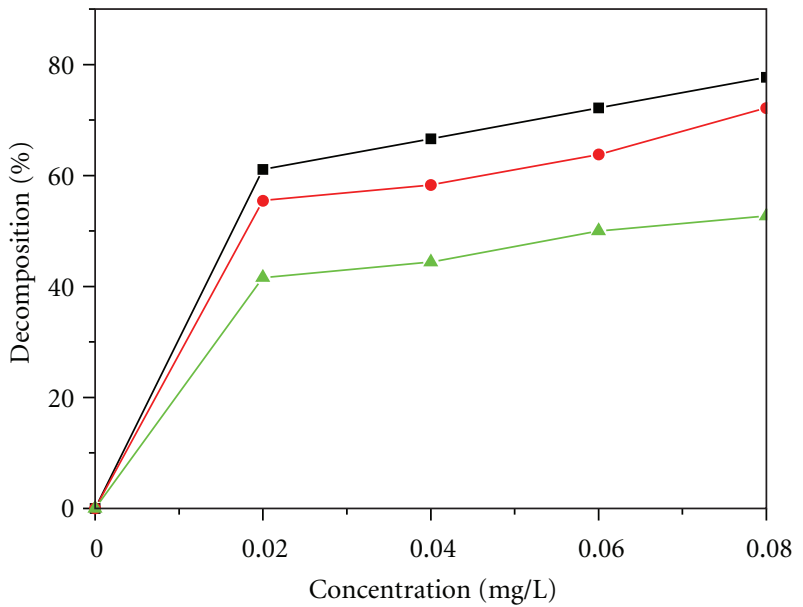

(b)

FIGURE 7: Effect of catalyst dosage on the photodegradation efficiency: (a) under sunlight and (b) under UV light irradiation: ( $\mathbf{\Delta})$ reagent grade $\mathrm{ZnO}$; $(\mathbf{\square}) 1 \%$ silver-doped $\mathrm{ZnO}$ with $0.3 \mathrm{M} n$-hexanol surface; $(\bullet) 3 \%$ silver-doped $\mathrm{ZnO}$ with $0.3 \mathrm{M} n$-hexanol surface modifier.

compared with UV light. In both the cases, higher efficiency was observed for photodegradation under sunlight rather than the UV light, because the UV light has an effect on the stability of the organic coating around the silver doped $\mathrm{ZnO}$ nanoparticles with longer UV exposures. Therefore, sunlight is better for surface modified silver doped $\mathrm{ZnO}$ designer nanoparticles. The increase in $\% T$ as well as photodegradation efficiency clearly represents the effective mineralization of the organics present in the municipal wastewater sample and brilliant blue dye solution using silver-doped $\mathrm{ZnO}$ designer particles.

3.6. Effect of $p H$ on \% T of Brilliant Blue Dye. The $p K a$ value of brilliant blue is 5.63 and 6.58 , which means that the $\mathrm{pH}$ has an effect on its photodegradation. The effect of $\mathrm{pH}$ is shown in Figure 9. The change in $\mathrm{pH}$ of the solution varies with the dissociation of the dye molecule and also the surface properties of the designer particles used. The initial adsorption of the dye molecules onto the polyscale crystals greatly depends on the solution $\mathrm{pH}$ [31]. Increase in the degradation efficiency under the alkaline conditions could be attributed to the increase in hydroxyl ions, which induce more hydroxyl radical formation. In acidic condition, the perhydroxyl radical can form hydrogen peroxide, which in turn gives rise to the hydroxyl radical.

This photocatalyst is more suitable for brilliant blue dye and effective, so that it can be used as an effective treatment method for textile industrial effluent. However, the municipal wastewater contains not only the toxic organics, but also the lots of other complex inorganics and heavy metals. This photocatalyst is less effective, and the maximum efficiency is only $69 \%$ for municipal wastewater. 


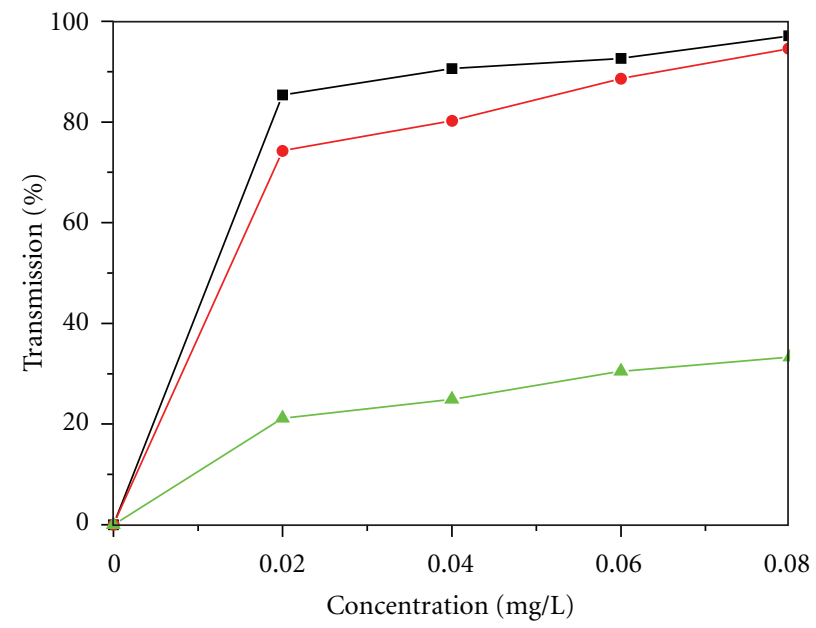

(a)

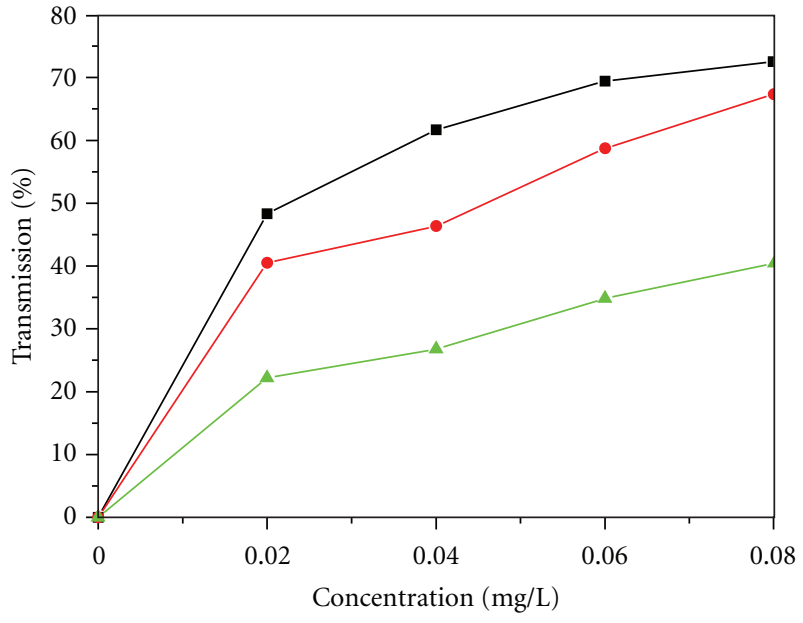

(b)

Figure 8: Effect of catalyst dosage on the \% $T$ of brilliant blue dye: (a) under sunlight and (b) under UV light irradiation: ( $\boldsymbol{\Delta}$ ) reagent grade $\mathrm{ZnO}$; (ם) $1 \%$ silver-doped $\mathrm{ZnO}$ with $0.3 \mathrm{M} n$-hexanol surface modifier; (•) $3 \%$ silver-doped $\mathrm{ZnO}$ with $0.3 \mathrm{M} n$-hexanol surface modifier.

TABLE 2: Photodegradation efficiency of the synthesized compounds with respect to weight and time under sunlight and UV light.

\begin{tabular}{lcccccc}
\hline \multirow{2}{*}{ Weight of catalyst } & \multicolumn{2}{c}{$\begin{array}{c}\text { \% Efficiency of surface-modified } \\
\text { silver- (1 mol\%) doped ZnO }\end{array}$} & \multicolumn{2}{c}{$\begin{array}{c}\text { \% Efficiency of surface-modified } \\
\text { silver- (3 mol\%) doped ZnO }\end{array}$} & \multicolumn{2}{c}{ \% Efficiency of reagent grade ZnO } \\
& sunlight & UV light & Sunlight & UV light & sunlight & UV light \\
\hline $10 \mathrm{mg}$ & 61.62 & 42.43 & 45.01 & 32.47 & 3.74 & 29.52 \\
$50 \mathrm{mg}$ & 66.42 & 47.23 & 49.44 & 36.9 & 3.85 & 30.62 \\
$70 \mathrm{mg}$ & 69.00 & 49.81 & 52.02 & 40.95 & 11.07 & 35.42 \\
\hline
\end{tabular}

Time: $3 \mathrm{~h}$.

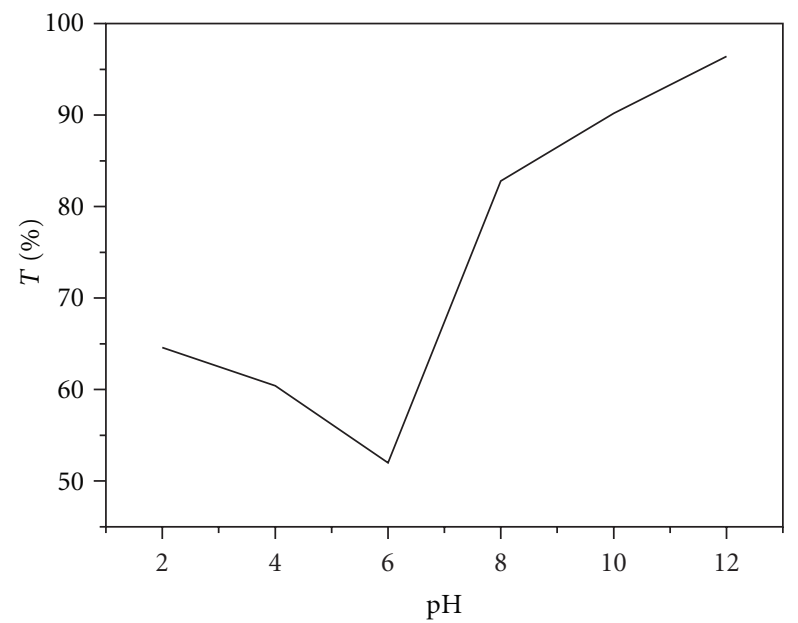

Figure 9: Effect of $\mathrm{pH}$ on $\% \mathrm{~T}$ of the brilliant blue dye (BBF).

\section{Conclusion}

Silver-doped $\mathrm{ZnO}$-modified designer particles were synthesized under mild hydrothermal conditions. $n$-hexanol was used as the surface modifier, because it has low toxicity, low density, and low melting temperature and also to obtain desired size and shape, enhances the reaction kinetics and synthesis is very rapid, we can synthesise nanoparticles in just a couple of hours, thereby reducing the experimental cost, and also it needs to low temperature for synthesis. XRD pattern demonstrates that the synthesized products are highly crystalline. In addition, FTIR spectra clearly represent the presence of $\mathrm{ZnO}$, dopants and organics. The SEM images clearly show that the crystals obtained are of various sizes and dispersibility. The use of sunlight as the source of illumination in the photodegradation reaction could be highly cost effective. The addition of surface modifier reduces the particle size avoid agglomeration and also it makes the synthesized compound highly hydrophilic which is necessary for achieving higher photodegradation efficiency. The municipal wastewater and brilliant blue dye were treated using the $\mathrm{ZnO}$ designer particles which clearly demonstrate that these compounds can be used for the treatment of other industrial effluents, particularly textile industry effluents.

\section{Acknowledgments}

The authors would like to thank Prof. R. Somashekar and Mr. P. Parameswara, Dept. of physics, University of Mysore, India for their kind help in carrying out this work was funded by The University Grants Commission, New Delhi. 


\section{References}

[1] A. S. Stasinakis, "Use of selected advanced oxidation processes (AOPs) for wastewater treatment-a mini review," Global NEST Journal, vol. 10, no. 3, pp. 376-385, 2008.

[2] K. Byrappa, K. M. Lokanatha Rai, and M. Yoshimura, "Hydrothermal preparation of $\mathrm{TiO}_{2}$ and photocatalytic degradation of hexachlorocyclohexane and dichlorodiphenyltrichloromethane," Environmental Technology, vol. 21, no. 10, pp. 1085-1090, 2000.

[3] C. Xiangfeng, J. Dongli, A. B. Djurišic, and Y. H. Leung, "Gassensing properties of thick film based on $\mathrm{ZnO}$ nanotetrapods," Chemical Physics Letters, vol. 401, no. 4-6, pp. 426429, 2005.

[4] C. A. K. Gouvêa, F. Wypych, S. G. Moraes, N. Durán, and P. Peralta-Zamora, "Semiconductor-assisted photodegradation of lignin, dye, and kraft effluent by Ag-doped $\mathrm{ZnO}$," Chemosphere, vol. 40, no. 4, pp. 427-432, 2000.

[5] S. H. Jo, J. Y. Lao, Z. F. Ren, R. A. Farrer, T. Baldacchini, and J. T. Fourkas, "Field-emission studies on thin films of zinc oxide nanowires," Applied Physics Letters, vol. 83, no. 23, pp. 48214823, 2003.

[6] H. S. Kang, J. S. Kang, J. W. Kim, and S. Y. Lee, "Effect of annealing on photoluminescence property of nano particle composite ZnO films," Applied Physics Letters, vol. 95, no. 3, pp. 1246-1250, 2004.

[7] M. Esmaili and A. Habibi-Yangjeh, "Preparation and characterization of $\mathrm{ZnO}$ nanocrystallines in the presence of an ionic liquid using microwave irradiation and photocatalytic activity," Journal of the Iranian Chemical Society, vol. 7, no. 1, pp. S70-S82, 2010.

[8] N. Daneshvar, S. Aber, and M. S. Seyed-Dorraji, "Influence of inorganic oxidants and metal ions on photocatalytic activity of prepared zinc oxide nanocrystals," Global Nest Journal, vol. 11, no. 4, pp. 535-545, 2009.

[9] R. Y. Hong, J. H. Li, L. L. Chen et al., "Synthesis, surface modification and photocatalytic property of $\mathrm{ZnO}$ nanoparticles," Powder Technology, vol. 189, no. 3, pp. 426-432, 2009.

[10] T. Adschiri and K. Byrappa, "Supercritical hydrothermal synthesis of organic-inorganic hybrid nanoparticles," in Nanohybridization of Organic-Inorganic Materials, A. Muramatsu, Ed., pp. 217-250, Springer, Berlin, Germany, 2009.

[11] K. Byrappa, "Novel hydrothermal solution routes of advanced high melting nanomaterials processing," Journal of the Ceramic Society of Japan, vol. 117, no. 1363, pp. 236-244, 2009.

[12] Y. L. Wu, F. Y. C. Boey, X. T. Zeng, X. H. Zhang, and A. I. Y. Tok, "Surface modification of ZnO nanocrystals," Applied Surface Science, vol. 253, no. 12, pp. 5473-5479, 2007.

[13] M. S. Tokumoto, V. Briois, C. V. Santilli, and S. H. Pulcinelli, "Preparation of $\mathrm{ZnO}$ nanoparticles: structural study of the molecular precursor," Journal of Sol-Gel Science and Technology, vol. 26, no. 1-3, pp. 547-551, 2003.

[14] J. H. Kim, W. C. Choi, H. Y. Kim, Y. Kang, and Y. K. Park, "Preparation of mono-dispersed mixed metal oxide micro hollow spheres by homogeneous precipitation in a micro precipitator," Powder Technology, vol. 153, no. 3, pp. 166-175, 2005.

[15] L. C. Damonte, L. A. Mendoza Zélis, B. Marí Soucase, and M. A. Hernández Fenollosa, "Nanoparticles of $\mathrm{ZnO}$ obtained by mechanical milling," Powder Technology, vol. 148, no. 1, pp. 15-19, 2004.
[16] M. L. Kahn, M. Monge, V. Collière, F. Senocq, A. Maisonnat, and B. Chaudret, "Size- and shape-control of crystalline zinc oxide nanoparticles: a new organometallic synthetic method," Advanced Functional Materials, vol. 15, no. 3, pp. 458-468, 2005.

[17] S. Komarneni, M. Bruno, and E. Mariani, "Synthesis of $\mathrm{ZnO}$ with and without microwaves," Materials Research Bulletin, vol. 35, no. 11, pp. 1843-1847, 2000.

[18] X. Zhao, B. Zheng, C. Li, and H. Gu, "Acetate-derived ZnO ultrafine particles synthesized by spray pyrolysis," Powder Technology, vol. 100, no. 1, pp. 20-23, 1998.

[19] Z. R. Dai, Z. W. Pan, and Z. L. Wang, "Novel nanostructures of functional oxides synthesized by thermal evaporation," Advanced Functional Materials, vol. 13, no. 1, pp. 9-24, 2003.

[20] W. Ao, J. Li, H. Yang, X. Zeng, and X. Ma, "Mechanochemical synthesis of zinc oxide nanocrystalline," Powder Technology, vol. 168, no. 3, pp. 148-151, 2006.

[21] K. Namratha, S. Suresha, M. B. Nayan, and K. Byrappa, "Synthesis, characterization and photocatalytic properties of silver doped ZnO," Research on Chemical Intermediates, vol. 37, no. 2-5, pp. 531-539, 2011.

[22] M. Yoshimura and K. Byrappa, "Hydrothermal processing of materials: past, present and future," Journal of Materials Science, vol. 43, no. 7, pp. 2085-2103, 2008.

[23] K. Byrappa and M. Yoshimura, Handbook of Hydrothermal Technology, Noyes Publications/William Andrew Publishing LLC, USA, 2001.

[24] R. E. Riman, W. L. Suchanek, K. Byrappa, C. W. Chen, P. Shuk, and C. S. Oakes, "Solution synthesis of hydroxyapatite designer particulates," Solid State Ionics, vol. 151, no. 1-4, pp. 393-402, 2002.

[25] K. Byrappa, M. H. Sunitha, A. K. Subram Ani et al., "Hydrothermal preparation of neodymium oxide coated titania composite designer particulates and its application in the photocatalytic degradation of procion red dye," Journal of Materials Science, vol. 41, no. 5, pp. 1369-1375, 2006.

[26] M. L. Foresti, M. Innocenti, and A. Hamelin, "Adsorption behavior of n-hexanol on $\mathrm{Ag}(111)$ from aqueous $0.05 \mathrm{M}$ KClO4," Langmuir, vol. 11, no. 2, pp. 498-505, 1995.

[27] H. Miyoshi, H. Ohno, K. Sakai, N. Okamura, and H. Kourai, "Characterization and photochemical and antibacterial properties of highly stable silver nanoparticles prepared on montmorillonite clay in n-hexanol," Journal of Colloid and Interface Science, vol. 345, no. 2, pp. 433-441, 2010.

[28] S. N. Yuen, S. M. Choi, D. L. Phillips, and C. Y. Ma, "Raman and FTIR spectroscopic study of carboxymethylated nonstarch polysaccharides," Food Chemistry, vol. 114, no. 3, pp. 1091-1098, 2009.

[29] B. Chiavarino, M. E. Crestoni, S. Fornarini, J. Lemaire, P. Maître, and L. MacAleese, " $\pi$-complex structure of gaseous benzene-NO cations assayed by IR multiple photon dissociation spectroscopy," Journal of the American Chemical Society, vol. 128, no. 38, pp. 12553-12561, 2006.

[30] B. Shahmoradi, I. A. Ibrahim, K. Namratha et al., "Surface modification of indium doped $\mathrm{ZnO}$ hybrid nanoparticles with n-butylamine," International Journal of Chemical Engineering Reaserch, vol. 2, no. 2, pp. 107-117, 2010.

[31] L. S. Murov, Handbook of Photochemistry, Marcel Dekker, New York, NY, USA, 1973. 


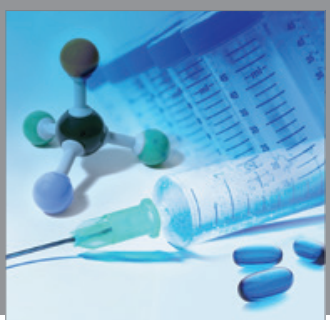

International Journal of

Medicinal Chemistry

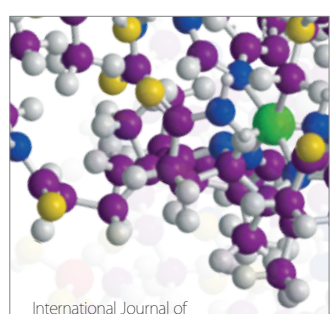

Carbohydrate Chemistry

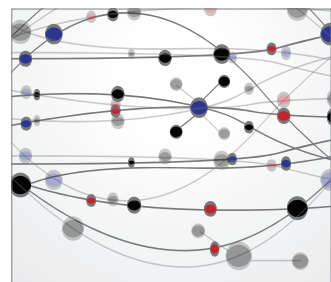

The Scientific World Journal
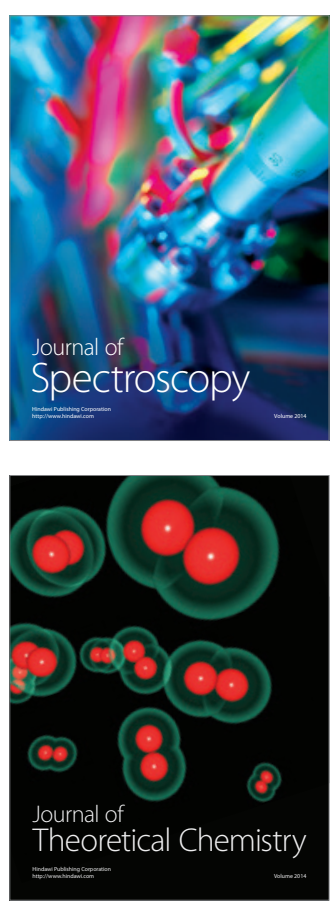
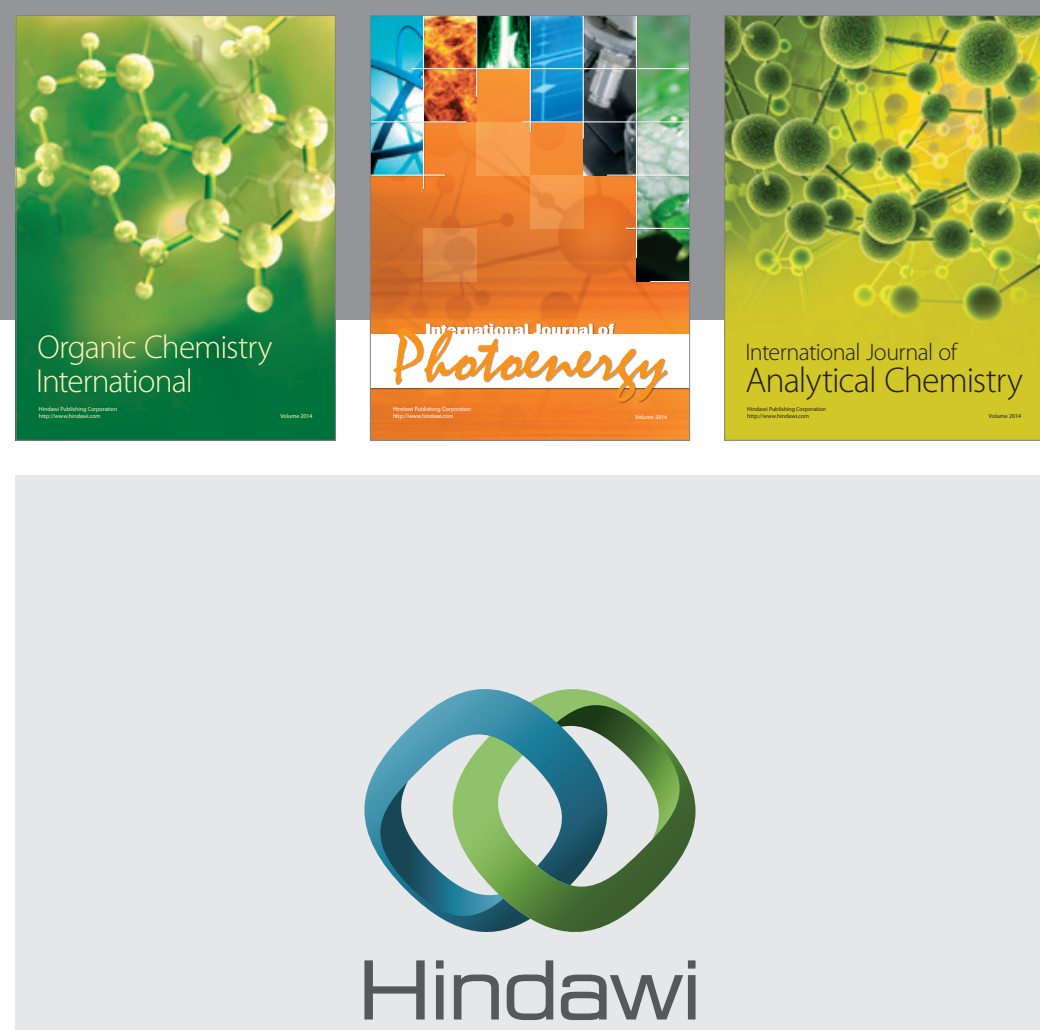

Submit your manuscripts at

http://www.hindawi.com
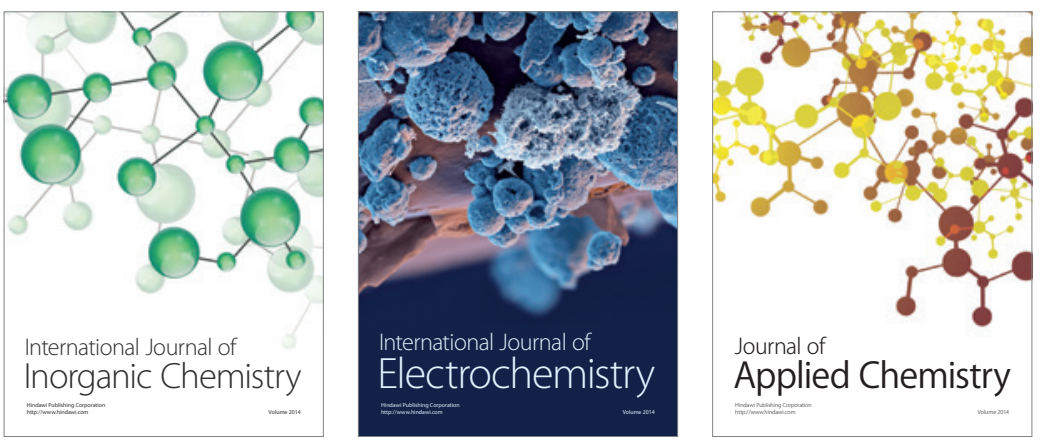

Journal of

Applied Chemistry
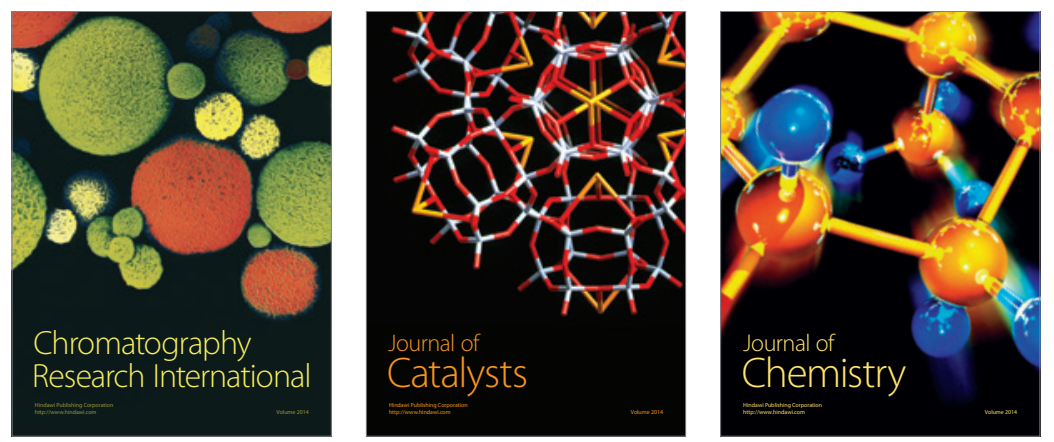
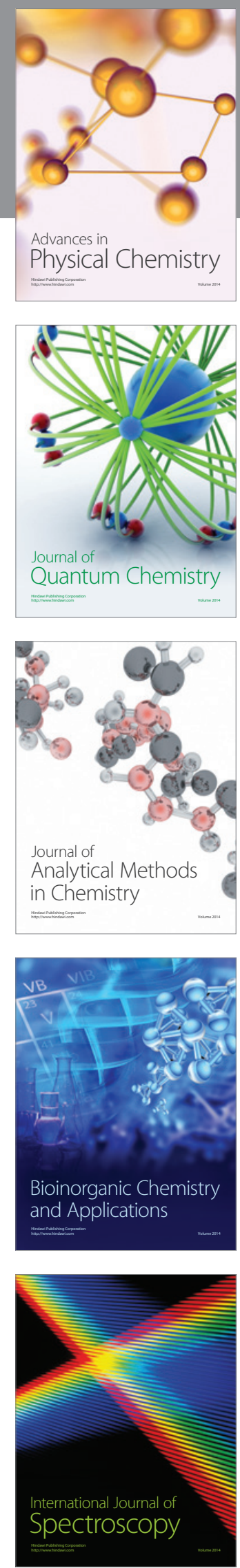